säureabsenkung auf unter $6 \mathrm{mg} / \mathrm{dl}$. Dieses Therapieziel wurde in der Praxis bei sehr vielen Patienten nicht erreicht. Der Effekt der Ernährung auf die Harnsäuresenkung ist begrenzt: Die meisten Experten beziffern ihn auf maximal 10-15\%. Die medikamentöse Standardtherapie mit dem Purinanalogon Allopurinol ist zwar effektiv. Aus Sorge vor dem Auftreten schwerer Hautreaktionen wird es aber häufig nur niedrig dosiert.

In zwei großen Studien, der APEX- und der FACT-Studie, an denen insgesamt 1832 Patienten mit Hyperurikämie und Gicht teilnahmen, war Febuxostat effektiver und dabei gleich gut verträglich, hat aber weni- ger zu beachtende Wechselwirkungen als Allopurinol. Primärer Endpunkt war in beiden Studien der Anteil der Patienten, bei denen eine Absenkung der Serum-Harnsäure unter $6 \mathrm{mg} / \mathrm{dl}$ gelang.

\section{Reduktion der Gichtanfälle auf nahezu Null}

Insgesamt 1086 Patienten der APEX- und FACT-Studien wurden in einer offenen Verlängerungsstudie (EXCEL) über weitere zwei Jahre beobachtet. Diese Studie zeigte, dass die dauerhafte Absenkung der Harnsäure unter $6 \mathrm{mg} / \mathrm{dl}$ zu einer progressiven Reduktion der Gichtanfälle auf nahezu Null bei Patienten führte, die eine Behandlung wegen eines akuten Gichtanfalls benötigten. Die Auflösung von Gichtknoten wurde in 46\% (80 mg Febuxostat), 36\% (120 mg Febuxostat) und 29\% (Allopurinol) erreicht.

Febuxostat ist zugelassen für die Therapie von Patienten mit chronischer Hyperurikämie bei Erkrankungen, die bereits zu Uratablagerungen geführt haben. Die empfohlene Dosis liegt bei $80 \mathrm{mg}$ täglich. Eine Erhöhung auf $120 \mathrm{mg}$ täglich kann erwogen werden, wenn die Serum-Harnsäure nach zwei bis vier Wochen Therapie den Zielbereich nicht erreicht hat.

- gvg

\title{
Neue Dreier-Fixkombination
}

\section{Auch bei schwer einstellbaren Hypertonikern rasch den Zielwert erreichen}

\begin{abstract}
- Etwa zwei Drittel der Bluthochdruckpatienten benötigen eine Kombinationstherapie mit Antihypertensiva verschiedener Wirkstoffklassen, um den Zielblutdruck von < 140/90 mmHg zu erreichen. Für die häufig älteren und komorbiden $\mathrm{Pa}$ tienten stellt die Einnahme mehrerer Tabletten aber eine Herausforderung dar. Die neue Dreier-Fixkombination Olmesartan/ Amlodipin/HCT (z. B. Sevikar $\mathrm{HCT}^{\circledR}$ ) kann Patienten, die durch eine lose Kombination dieser Wirkstoffe bereits adäquat eingestellt sind, die Behandlung vereinfachen und zu einer Verbesserung der Compliance beitragen, so Prof. Dr. Reinhold Kreutz, Berlin.
\end{abstract}

\section{Tiple- der Zweifach-Kombination überlegen}

Die Daten der multizentrischen, randomisierten doppelblinden TRINITY-Studie bei 2492 Patienten mit mäßiger bis schwerer Hypertonie zeigen, dass die Triple-Kombination Olmesartan/Amlodipin/HCT (40/ 10/25 mg) den Blutdruck effektiver reduziert als die jeweiligen Zweifachkombinationen der einzelnen Komponenten [Oparil $S$ et al. 2010]. Nach zwölf Wochen sank der Blutdruck um durchschnittlich 37,1/21,8 mmHg. Über zwei Drittel (69,9\%) der mit

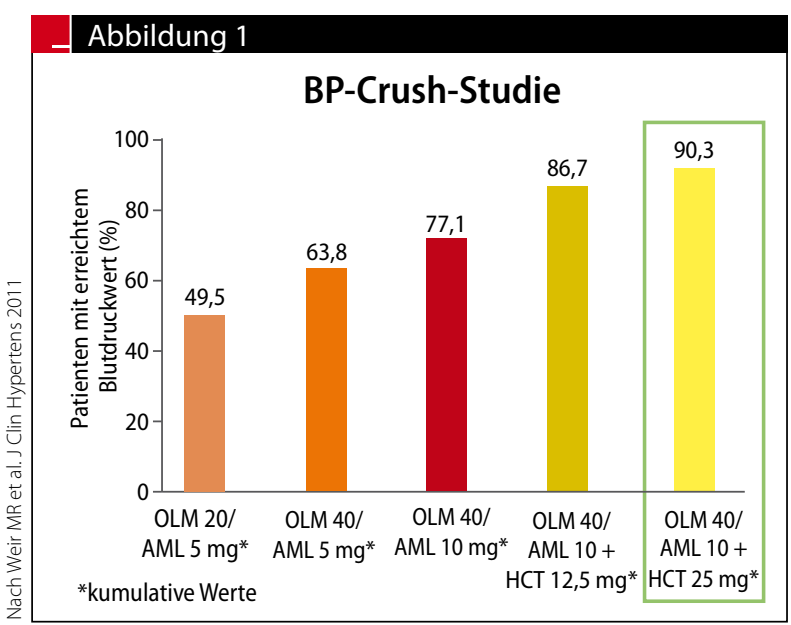

Abb. 1 Erreichte RR-Wert $<140 / 90 \mathrm{mmHg}$ innerhalb der jeweiligen Dosierungsstufen (OLM = Olmesartan, AML = Amlodipin).

der Dreierkombination behandelten Patienten erreichten die individuellen Blutdruckzielwerte im Vergleich zu 52,9\%, $53,4 \%$ und $41,1 \%$ unter den Zweifachkombinationen $(p<0,001)$. Die Wirkung setzte innerhalb von zwei Wochen ein. Am Studieende betrug der zusätzliche blutdrucksenkende Effekt der Dreifach- gegenüber den Zweifachkombinationen für den diastolischen Blutdruck im Sitzen zwischen $-3,8$ und $-6,7 \mathrm{mmHg}$ und für den systo- lischen Blutdruck im Sitzen zwischen $-7,1$ und $-9,6$ $\mathrm{mmHg}$.

Die Ergebnisse der TRINITY-Studie wurden in der prospektiven, multizentrischen Titrationsstudie BP-Crush bestätigt, berichtete Prof. Dr. Eva Brand, Münster. Die 999 Studienteilnehmer waren durch eine Monotherapie nicht einstellbar und erhielten zunächst Olmesartan plus Amlodipin. Wurde auch mit der Zweifachkombination keine Werte $<140 / 90$ $\mathrm{mmHg}$ erreicht, erhielten die Patienten nach zwölf Wochen zusätzlich noch HCT. Unter der Dreifachkombination erreichten nach weiteren neun Wochen 90,3\% der schwer einstellbaren Patienten die Blutdruckzielwerte (Abb. 1)

- Abdol A. Ameri

Quelle: Satellitensymposium „Kombinationsstrategien mit dem $\mathrm{AT}_{1}$-Blocker: Olmesartan - Synergien für die Therapie der Hypertonie nutzen“, DGIM-Kongresses, Wiesbaden, Mai 2011 (Veranstalter: Daiichi Sankyo) 